\title{
The Uptake and Production of Molecular Hydrogen by Unicellular Cyanobacteria
}

\author{
By DAVID C. HOWARTH† AND GEOFFREY A. CODD* \\ Department of Biological Sciences, University of Dundee, Dundee DDI 4HN, UK
}

(Received 9 July 1984; revised 14 January 1985)

\begin{abstract}
Nine strains of unicellular non-nitrogen-fixing cyanobacteria had high rates of hydrogen evolution and uptake compared with filamentous nitrogen-fixing strains. Maximal hydrogen uptake activities were observed in assays including oxygen under both light and dark conditions suggesting the participation of the 'Knallgas' reaction. Nitrogenase activity, measured as acetylene reduction, was not found in aerobic cultures of any of the unicellular strains tested, and the capacity to synthesize nitrogenase under anaerobic conditions was absent in all five of the strains tested under these conditions. Thus the capacity to synthesize nitrogenase is not a prerequisite for hydrogenase synthesis and hydrogen evolution by these unicellular cyanobacteria. Rates of hydrogen evolution and uptake by six of the unicellular strains were increased following adaptation with $\mathrm{CO}_{2} / \mathrm{H}_{2}$ gas mixtures.
\end{abstract}

\section{INTRODUCTION}

Hydrogenase, which reversibly activates molecular hydrogen, is believed to be present whenever hydrogen is evolved or consumed by micro-organisms, the notable exception being the ATP-dependent evolution of hydrogen observed under certain physiological conditions, which is catalysed by nitrogenase (Stewart, 1980; Bothe, 1982).

Gaffron \& Rubin (1942) reported hydrogen formation by an anaerobically incubated culture of the green alga Scenedesmus obliquus, and though a reversible hydrogenase was demonstrated in a unicellular cyanobacterium, Synechococcus elongatus, following anaerobic pre-incubation (Frenkel et al., 1950), green algae were long preferred to cyanobacteria for experimental work.

Hydrogen formation due to a cyanobacterial nitrogenase in vitro was first demonstrated in the nitrogen-fixing cyanobacterium, Anabaena cylindrica (Haystead et al., 1970), and it is generally agreed that nitrogenase-mediated hydrogen evolution in cyanobacteria and other photosynthetic bacteria are similar processes which have all the characteristics of a nitrogenase system requiring light-generated ATP (light-dependence on photosystem I only, sensitivity to uncouplers of photophosphorylation and inhibition by nitrogen but not carbon monoxide). Hydrogen production by nitrogen-fixing cells and nitrogen fixation (acetylene reduction) decrease in parallel when fixed nitrogen is added to the culture medium (Stewart, 1980), and the use of carbon monoxide and acetylene at concentrations shown to inhibit uptake hydrogenase activities has provided evidence that a natural function of hydrogenase may be to recycle hydrogen lost by nitrogenase, thereby reducing the energy loss inherent in this process.

As hydrogen evolution due to nitrogenase action is irreversible, all known cyanobacterial hydrogen uptake reactions are presumed to be mediated by hydrogenase. Hydrogen uptake has been shown to occur filamentous cyanobacteria, irrespective of whether they fix nitrogen, and Tel-Or et al. (1977) demonstrated an increase in hydrogenase activity in Anabaena cylindrica and Nostoc muscorum cultures grown under hydrogen. Eisbrenner et al. (1978) reported similar

† Present address: Department of Microbiology, University of Leeds, Leeds LS2 9JT, UK.

Abbreviations: chl, chlorophyll $a$; DCMU, $N^{\prime}$-(3,4-dichlorophenyl)- $N, N$-dimethylurea. 
results in a range of cyanobacteria including a unicellular non-nitrogen-fixer, Anacystis nidulans (Synechococcus). Evidence suggests that cyanobacterial hydrogenase is multifunctional as envisaged by Dixon (1972) for aerobic nitrogen-fixing organisms such as rhizobia. In cyanobacteria, the oxygen-dependent hydrogen uptake proceeds via the respiratory chain, providing additional ATP for cellular metabolism (Bothe et al., 1977b; Peterson \& Burris, 1978), an additional supply of reducing equivalents for nitrogen fixation and the removal of oxygen from the nitrogenase site, thereby protecting the enzyme from damage by this gas (Bothe et al., $1977 b$; Gallon, 1981).

Peschek (1979a,b,c) has studied hydrogen metabolism in Anacystis nidulans 1402-1 (Synechococcus 6301) and his results indicate a membrane-bound hydrogenase involved in phosphorylative electron flow from hydrogen to oxygen via the respiratory chain, and a membrane-bound 'photoreduction' hydrogenase initiating a light-driven electron flow from hydrogen to various low potential acceptors, including endogenous ferredoxin, though as yet it is unclear whether two distinct functional enzymes are involved. Other work on hydrogen metabolism by unicellular cyanobacteria has involved the use of field isolates selected for hydrogen evolution due to nitrogenase, although pure cultures were not used (Berchtold \& Bachofen, 1979). This communication details studies on hydrogen metabolism in nine pure cultures of unicellular cyanobacteria which do not exhibit nitrogenase activity.

\section{METHODS}

Cyanobacteria and culture conditions. The following unicellular strains were obtained from the Institut Pasteur, Paris (earlier names are given in parentheses, see Rippka et al., 1979): Synechococcus PCC 6307 (Coccochloris peniocystis), Synechoccus PCC 6301 (Anacystis nidulans), Synechocystis 6714 (Aphanocapsa sp.), Synechocystis 6308 (Aphanocapsa and Gloeocapsa alpicola), Gloeobacter 7421, Microcystis 7820. Synechococcus strains 6308 and 602 were a gift from Dr S. V. Shestakov, Moscow State University, USSR, and Aphanocapsa montana was provided by Dr R. A. Lewin, Scripps Institute of Oceanography, La Jolla, Calif., USA.

All strains were grown axenically and photoautotrophically in BG11 medium (Stanier et al., 1971), which contained (g l-1): $\mathrm{NaNO}_{3}(1.5), \mathrm{K}_{2} \mathrm{HPO}_{4}(0.04), \mathrm{MgSO}_{4} .7 \mathrm{H}_{2} \mathrm{O}(0.075), \mathrm{CaCl}_{2} .2 \mathrm{H}_{2} \mathrm{O}(0.036)$, citric acid (0.006), ferric ammonium citrate (0.006), EDTA (magnesium salt) $(0.001), \mathrm{Na}_{2} \mathrm{CO}_{3}(0.02)$, and a trace metals solution at a final concentration of $1 \mathrm{ml} \mathrm{l} \mathbf{l}^{-1}$. The trace metals solution contained $\left(\mathrm{g} \mathrm{l}^{-1}\right): \mathrm{H}_{3} \mathrm{BO}_{3}(2 \cdot 86), \mathrm{ZnSO}_{4} \cdot 7 \mathrm{H}_{2} \mathrm{O}(0 \cdot 222)$, $\mathrm{Na}_{2} \mathrm{MoO}_{4} .2 \mathrm{H}_{2} \mathrm{O}(0.39), \mathrm{CuSO}_{4} .5 \mathrm{H}_{2} \mathrm{O}(0.79)$, and $\mathrm{Co}\left(\mathrm{NO}_{3}\right)_{2} .6 \mathrm{H}_{2} \mathrm{O}(0.049)$. Following autoclaving and cooling, the $\mathrm{pH}$ of the medium was $7 \cdot 1$. Cultures were grown in Erlenmeyer flasks at 25 to $30^{\circ} \mathrm{C}$ and a photon fluence rate of $20 \mu \mathrm{mol} \mathrm{m} \mathrm{m}^{-2} \mathrm{~s}^{-1}$, which was provided at the surface of the flasks by white fluorescent tubes. All cultures were continuously agitated on an MSE orbital shaker. For $\mathrm{CO}_{2} / \mathrm{H}_{2}$ adaptation experiments, cells were grown in Quickfit flasks, equipped with two-way adaptors and air filters, in an identical manner to aerobically-grown cultures. Cultures were also maintained and checked for purity on agar plates (final concentration $0.8 \%, \mathrm{w} / \mathrm{v}$ ) prepared by mixing autoclaved double strength Oxoid Technical Agar no. 3 with autoclaved double strength BG11 medium in equal proportions.

Measurement of hydrogen uptake by whole cells. The uptake of molecular hydrogen was measured using $5 \mathrm{ml}$ cells in gas-tight $30 \mathrm{ml} \mathrm{McCartney} \mathrm{bottles.} \mathrm{The} \mathrm{bottles} \mathrm{were} \mathrm{flushed} \mathrm{with} \mathrm{argon} \mathrm{for} 20 \mathrm{~min}$ and hydrogen was syringed into the bottles to start the reaction. Hydrogen uptake rates were linear throughout the incubation period for up to $4 \mathrm{~h}$, and were measured by injecting $0.25 \mathrm{ml}$ gas samples into a Perkin-Elmer F-30 gas liquid chromatograph equipped with a molecular sieve column and a thermal conductivity detector with argon as the carrier gas. The bottles were shaken under light at a photon fluence rate of 20 to $30 \mu \mathrm{mol} \mathrm{m}^{-2} \mathrm{~s}^{-1}$.

Measurement of hydrogen evolution by whole cells. Hydrogen evolution was measured using $3 \mathrm{ml}$ cell suspensions in gas-tight Bijou bottles of approximate internal volume $7.8 \mathrm{ml}$ under an atmosphere of argon. The suspensions were flushed with argon for $20 \mathrm{~min}$ and the bottles shaken under light at a photon fluence rate of 20 to $30 \mu \mathrm{mol} \mathrm{m} \mathrm{m}^{-2} \mathrm{~s}^{-1} .1 \mathrm{ml}$ gas samples were removed after a given time period and assayed using the Perkin-Elmer gas liquid chromatograph. Rates of hydrogen evolution were observed to be linear for at least 5 to $6 \mathrm{~h}$.

Measurement of nitrogenase activity. The acetylene reduction method (Stewart et al., 1967) was used. Experiments were done in Bijou bottles under argon. Cell suspensions $(3 \mathrm{ml})$ were routinely flushed with argon for $20 \mathrm{~min}$, acetylene of a given concentration was syringed into the bottle, and the bottles were continuously agitated under a photon fluence rate of 20 to $30 \mu \mathrm{mol} \mathrm{m}^{-2} \mathrm{~s}^{-1}$ for light assays. Gas samples of known volume were assayed using a Varian gas liquid chromatograph, model 940 (Varian Associates, Walton-on-Thames, UK), equipped with a flame ionization detector and a Porapak $\mathrm{R}$ column. Results were calculated using both the acetylene and ethylene peaks obtained from the chromatograph. Cells were grown in BGll medium containing nitrate and resuspended in either fresh BG11 containing nitrate or BG11 medium without nitrate for the determination of acetylene reduction activity. Thus nitrogenase activity was tested both in the presence and absence of combined nitrogen. 
Attempts were made to induce nitrogenase synthesis and activity in the unicellular cyanobacteria by imposing anaerobiosis as described by Rippka \& Waterbury (1977).

Ly'sozyme treatment of cells. In certain experiments, cells were treated with lysozyme in an attempt to permit the entry of inhibitors. Cell suspensions were incubated with lysozyme (Grade 1, Sigma), at a final concentration of $1 \mathrm{mg}$ per $\mathrm{ml}$ cyanobacterial culture, for $45 \mathrm{~min}$ at 25 to $30^{\circ} \mathrm{C}$ with constant shaking.

Adaptation of cultures with molecular hydrogen. Cultures were grown under a gas mixture of $5 \%(\mathrm{v} / \mathrm{v})$ carbon dioxide in hydrogen, before being grown aerobically for $4 \mathrm{~d}$ and then transferred back to growth under $5 \%$ carbon dioxide in hydrogen.

Other methods. The growth of cultures was monitored by measuring their optical density using an EEL colorimeter with a red OR1 filter. Chlorophyll $a$ concentrations were measured by methanol extraction (MacKinney, 1941). Dry weight determinations were made by filtering $5 \mathrm{ml}$ cell suspensions onto a pre-dried, preweighed Whatman GF/C filter disc and drying to a constant weight at $60^{\circ} \mathrm{C}$.

Chemicals and gases. Lysozyme, antimycin A and rotenone were obtained from Sigma and all other chemicals were from BDH. All gases were from Air Products, Glasgow, UK, except acetylene and ethylene which were obtained from the British Oxygen Company.

\section{RESULTS}

\section{Uptake of molecular hydrogen}

Experiments were done with Synechococcus strains 6803 and 6301 to elucidate the mechanism of hydrogen uptake by these organisms. Hydrogen was consumed in an oxygen-requiring 'Knallgas' type of reaction with an optimal oxygen concentration between 1.0 and $1.5 \mathrm{mmol} \mathrm{l}^{-1}$. Additionally, experiments in which the hydrogen concentration was varied showed the optimum to be about $1.0 \mathrm{mmol}^{-1}$. Hence for the measurement of hydrogen uptake by whole cells $1.05 \mathrm{mmol} \mathrm{l}^{-1}$ hydrogen and $1.05 \mathrm{mmol} \mathrm{l}^{-1}$ oxygen were used throughout. Table 1 shows the extent of hydrogen uptake by the nine strains grown photoautotrophically in pure culture. All the strains consumed molecular hydrogen, though variation occurred between strains. Although the rates observed with certain strains were low, these rates were reproducible and were found to be linear over 5 h. Certain strains (Microcystis 7820, Synechococcus strains 6307 and 6301) had low rates of hydrogen uptake, whereas others (e.g. Synechococcus strains 6803 and 602, Synechocystis 6308 and Gloeobacter 7421) had higher rates of hydrogen uptake. All the strains were cultured on BG11 medium containing nitrate. They have been shown by Rippka and coworkers (see Rippka et al., 1979), and in this paper, not to possess detectable nitrogenase activity. Maximal hydrogen uptake activities were usually observed in the presence of oxygen, either under light or dark conditions, suggesting the participation of the 'Knallgas' reaction. Little or no hydrogen uptake was observed in assays where the concentration of oxygen was low, i.e. in the presence of DCMU in the light and in dark assays without oxygen addition. Rates of hydrogen consumption by Synechococcus 6301 were higher than the value of $6 \mu \mathrm{mol} \mathrm{H} \mathrm{H}_{2} \mathrm{~h}^{-1}$ $(\mathrm{mg} \mathrm{chl})^{-1}$ reported earlier for light plus added oxygen-dependent uptake by this strain (Eisbrenner et al., 1981), though rates of hydrogen uptake and evolution by cyanobacteria reported by different laboratories of ten vary and explanations have been proposed to account for this (Bothe et al., 1978).

\section{Effect of selected electron transport inhibitors on hydrogen uptake}

As the results in Table 1 suggested the participation of a 'Knallgas' type reaction, presumably involving a membrane-bound respiratory electron transport chain, the action of the electron transport chain inhibitors antimycin A, rotenone and $\mathrm{KCN}$ was tested on hydrogen uptake by Synechococcus strains 6803 and 6301. Experiments were done with lysozyme-treated cells (see Methods) to facilitate the entry of inhibitors into the cells, and with control cells (not lysozymetreated). Rates of hydrogen uptake by both strains were higher in lysozyme-treated cells than in untreated cells (Table 2), and the treated cells were used to determine the extent of inhibition of hydrogen uptake. Respiratory chains have to date been little characterized in cyanobacteria, although it is safe to assume that they possess segments of the respiratory chain in common with mitochondria and other bacteria (Gel'man et al., 1967; Lemberg \& Barrett, 1973). KCN, an inhibitor of terminal respiratory cytochrome oxidase, completely inhibited hydrogen uptake by both Synechococcus strains. Rotenone, a flavoprotein inhibitor (Chance \& Hollunger, 1963), 
Table 1. Uptake of molecular hydrogen by nine strains of unicellular cyanobacteria

All assays were done in duplicate or quadruplicate. Hydrogen uptake was monitored as the disappearance of hydrogen from the gas phase. Concentrations of both hydrogen and oxygen in the assay were both initially $1.05 \mathrm{mmol}^{-1}$. DCMU was added to a final concentration of $5 \cdot 4 \times$ $10^{-6} \mathrm{~mol}^{-1} 1^{-1}$. Boiled cell controls were done for each of the nine strains and the values obtained (approximately $5 \%$ of the rates found with living cells) were subtracted from the values obtained in each of the nine assays. Chlorophyll $a$ concentrations in all experiments were between 3 and $5 \mu \mathrm{g} \mathrm{ml}^{-1}$. The photon fluence rate was $30 \mu \mathrm{mol} \mathrm{m}^{-2} \mathrm{~s}^{-1}$. ND, Not determined.

\begin{tabular}{|c|c|c|c|c|c|}
\hline \multirow[b]{2}{*}{ Strain } & \multicolumn{5}{|c|}{ Hydrogen uptake $\left[\mu \mathrm{mol} \mathrm{H}_{2} \mathrm{~h}^{-1}(\mathrm{mg} \mathrm{chl})^{-1}\right]$} \\
\hline & $\begin{array}{c}\text { Light } \\
\text { only }\end{array}$ & $\begin{array}{l}\text { Light } \\
+\mathrm{O}_{2}\end{array}$ & $\begin{aligned} & \text { Light } \\
+ & \mathrm{DCMU}\end{aligned}$ & $\begin{array}{c}\text { Dark } \\
\text { only }\end{array}$ & $\begin{array}{l}\text { Dark } \\
+\mathrm{O}_{2}\end{array}$ \\
\hline Synechococcus 6803 & $42 \cdot 22$ & $33 \cdot 38$ & $10 \cdot 76$ & $12 \cdot 76$ & $14 \cdot 73$ \\
\hline Synechococcus 602 & 0 & $32 \cdot 40$ & ND & 0 & $29 \cdot 46$ \\
\hline Synechococcus 6301 & $0 \cdot 98$ & $12 \cdot 76$ & 3.92 & $13 \cdot 74$ & $14 \cdot 73$ \\
\hline Synechococcus 6307 & 13.74 & 16.69 & ND & 0 & 2.94 \\
\hline Microcystis 7820 & 8.83 & $5 \cdot 89$ & 0 & 0 & 0.98 \\
\hline Gloeobacter 7421 & $5 \cdot 89$ & $98 \cdot 20$ & $8 \cdot 83$ & $33 \cdot 38$ & $55 \cdot 97$ \\
\hline Synechocystis 6308 & $2 \cdot 94$ & $54 \cdot 01$ & $7 \cdot 85$ & 0 & $56 \cdot 95$ \\
\hline Synechocystis 6714 & $11 \cdot 78$ & $20 \cdot 62$ & ND & 0 & $14 \cdot 73$ \\
\hline Aphanocapsa montana & $15 \cdot 71$ & $29 \cdot 46$ & 0 & ND & $27 \cdot 49$ \\
\hline
\end{tabular}

\title{
Table 2. Uptake of hydrogen by Synechococcus strains 6803 and 6301: the effect of electron transport chain inhibitors
}

\begin{abstract}
Oxygen and hydrogen were initially present in all assays at $1.5 \mathrm{mmol}^{-1}$. Duplicate assays were done under a microaerobic atmosphere of argon after an argon flushing period of $20 \mathrm{~min}$. The photon fluence rate was $30 \mu \mathrm{mol} \mathrm{m}^{-2} \mathrm{~s}^{-1}$. Hydrogen uptake rates were measured over $4 \mathrm{~h}$ following the commencement of the assays. Potassium cyanide was added dissolved in water. Antimycin A and rotenone were added dissolved in ethanol; ethanol-only controls were run and the hydrogen uptake rates were the same as those measured in light + oxygen assays in both lysozyme-treated and untreated cells. The final concentrations of the inhibitors were: antimycin A, $3 \times 10^{-4} \mathrm{~mol} \mathrm{l}^{-1}$; rotenone, $10^{-5} \mathrm{~mol}^{-1}$ and $\mathrm{KCN}, 10^{-3} \mathrm{~mol} \mathrm{l}^{-1}$. The chlorophyll $a$ concentrations were: Synechococcus $6803,2 \cdot 57 \mu \mathrm{g} \mathrm{ml}^{-1}$ and Synechococcus $6301,2 \cdot 60 \mu \mathrm{g} \mathrm{ml}^{-1}$.
\end{abstract}

\begin{tabular}{|c|c|c|c|}
\hline \multirow[b]{2}{*}{ Inhibitor } & \multirow[b]{2}{*}{ Lysozyme } & \multicolumn{2}{|c|}{$\begin{array}{c}\text { Hydrogen uptake } \\
{\left[\mu \mathrm{mol} \mathrm{H}_{2} \mathrm{~h}^{-1}(\mathrm{mg} \mathrm{chl})^{-1}\right]}\end{array}$} \\
\hline & & Synechococcus 6803 & Synechococcus 6301 \\
\hline- & + & $25 \cdot 92$ & $21 \cdot 70$ \\
\hline - & - & $23 \cdot 56$ & $11 \cdot 39$ \\
\hline Potassium cyanide & + & 0 & 0 \\
\hline Potassium cyanide & - & 0 & 0 \\
\hline Rotenone & + & $9 \cdot 42$ & 0 \\
\hline Rotenone & - & $14 \cdot 14$ & $9 \cdot 72$ \\
\hline Antimycin A & + & $1 \cdot 17$ & 6.48 \\
\hline Antimycin A & - & $29 \cdot 46$ & 0 \\
\hline
\end{tabular}

completely inhibited hydrogen uptake by lysozyme-treated Synechococcus 6301 and caused a $64 \%$ inhibition of hydrogen-uptake in the light control by Synechococcus 6803. Antimycin A, which inhibits electron transfer between cytochromes $b$ and $c$ in mitochondria (Rieske \& Zaugg, 1962), caused a $70 \%$ inhibition and a $95 \%$ inhibition of the lysozyme-treated light control rates in strains 6301 and 6803 respectively. A lack of inhibitory effects on respiration by antimycin $A$ has previously been reported in cyanobacteria (Biggins, 1969; Bothe et al., 1977b; Peschek, 1980), although Houchins \& Burris (1981) reported an inhibition of light and dark hydrogen uptake reactions in membrane particles from Anaebaena 7120 by $50 \mu \mathrm{M}$-antimycin A. The results in Table 2 therefore suggest that such hydrogen uptake, functioning maximally in the presence of oxygen, may involve a typical respiratory electron transport chain with oxygen as the terminal acceptor. 


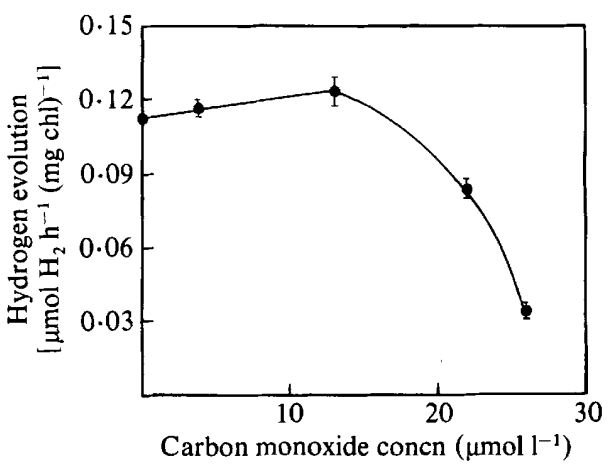

Fig. 1. Effect of carbon monoxide on hydrogen evolution by Synechococcus 6803 . Assay mixtures were incubated for $3 \mathrm{~h}$ under an atmosphere of argon, following a period of argon flushing of $20 \mathrm{~min}$. Points are the mean of duplicate assay determinations; variation is denoted by the vertical bars. The photon fluence rate was $30 \mu \mathrm{mol} \mathrm{m}^{-2} \mathrm{~s}^{-1}$ and the chlorophyll $a$ concentration was $4.295 \mu \mathrm{g} \mathrm{ml}^{-1}$.

\section{Table 3. Evolution of molecular hydrogen by unicellular cyanobacteria}

All values are the means of triplicate assays. Carbon monoxide and acetylene were present in the assays at final concentrations of $13.4 \mu \mathrm{mol} \mathrm{l}^{-1}$ and $1.34 \mathrm{mmol} \mathrm{l}^{-1}$ respectively. All assays were done under a microaerobic atmosphere of argon, following an argon flushing period of $20 \mathrm{~min}$, and were incubated for $3 \mathrm{~h}$. Chlorophyll $a$ concentrations were between 3 and $5 \mu \mathrm{g} \mathrm{ml}^{-1}$. The photon fluence rate was $30 \mu \mathrm{mol} \mathrm{m} \mathrm{m}^{-2} \mathrm{~s}^{-1}$.

\begin{tabular}{|c|c|c|c|c|c|}
\hline \multirow[b]{2}{*}{ Strain } & \multicolumn{5}{|c|}{ Hydrogen evolution $\left[\mu \mathrm{mol} \mathrm{H}_{2} \mathrm{~h}^{-1}(\mathrm{mg} \mathrm{chl})^{-1}\right]$} \\
\hline & $\begin{array}{c}\text { Light } \\
\text { only }\end{array}$ & $\begin{array}{c}\text { Light } \\
\mathrm{CO}+\mathrm{C}_{2} \mathrm{H}_{2}\end{array}$ & $\begin{array}{c}\text { Light } \\
\mathrm{CO} \text { only }\end{array}$ & $\begin{array}{c}\text { Light } \\
\mathrm{C}_{2} \mathrm{H}_{2} \text { only }\end{array}$ & $\begin{array}{c}\text { Dark } \\
\mathrm{CO}+\mathrm{C}_{2} \mathrm{H}_{2}\end{array}$ \\
\hline Synechococcus 6803 & $0 \cdot 11$ & $0 \cdot 17$ & $0 \cdot 12$ & $0 \cdot 20$ & $0 \cdot 26$ \\
\hline Synechococcus 602 & 0.48 & 0.61 & 0.66 & $0 \cdot 31$ & 0.66 \\
\hline Synechococcus 6301 & 0.08 & 0.08 & 0.02 & 0.09 & 0.08 \\
\hline Synechococcus 6307 & 0.02 & 0.01 & 0 & 0 & 0 \\
\hline Microcystis 7820 & $0 \cdot 11$ & $0 \cdot 16$ & $0 \cdot 11$ & $0 \cdot 15$ & 0.02 \\
\hline Gloeobacter 7421 & $0 \cdot 60$ & $1 \cdot 38$ & 0.36 & 0.69 & 0.59 \\
\hline Synechocystis 6308 & 0.06 & 0.13 & 0.07 & 0.03 & 0.07 \\
\hline Synechocystis 6714 & 0.04 & 0.05 & 0.07 & 0.03 & 0.07 \\
\hline Aphanocapsa montana & 0.40 & 0.23 & $0 \cdot 19$ & 0.28 & 0.06 \\
\hline
\end{tabular}

\section{Hydrogen evolution}

Preliminary time course experiments showed that Synechococcus strains 6803 and 6301 had linear rates of hydrogen evolution over $5 \mathrm{~h}$. The effect of carbon monoxide on hydrogen evolution by Synechococcus 6803 was determined (Fig. 1). A slight increase in the rate of hydrogen evolution occurred up to about $13 \mu \mathrm{M}$-carbon monoxide, although rates decreased at higher concentrations. This slight initial stimulation and subsequent inhibition of hydrogen production at increasing carbon monoxide concentrations found in a unicellular strain where nitrogenase activity was not detectable requires an explanation for carbon monoxide effects on hydrogenase rather than nitrogenase. Observations of hydrogen evolution by Synechococcus strains 6803 and 6301 in the light were extended to the remaining seven strains. The effects of carbon monoxide and acetylene on hydrogen evolution rates were assessed; in particular it was determined whether the use of those gases together would stimulate hydrogen evolution, as shown for nitrogen-fixing Anabaena cylindrica (Bothe et al., 1977a). All strains evolved hydrogen (Table 3), although the rates of evolution by Synechococcus 6301, Synechocystis 6714 and Microcystis 7820 were very low, and Synechococcus 6307 had virtually no capacity to evolve hydrogen. In contrast, Synechococcus strains 6803 and 602, Gloeobacter 7421 and Aphanocapsa 
montana had relatively high rates of hydrogen evolution, which varied according to the assay conditions and are of interest considering that nitrogenase, which is believed to be primarily responsible for hydrogen evolution in filamentous cyanobacteria (Bothe et al., 1978), is undetectable in all of these unicells by the acetylene reduction method (see below). The low rates of hydrogen evolution by Synechocystis strains 6308 and 6714, Mycrocystis 7820 and Synechococcus 6301 were virtually unaffected by changes in the assay conditions (Table 3), suggesting the presence of a low basal capacity for hydrogen evolution in these strains, which may be due to the uptake hydrogenase acting in a reversible manner. The four strains showing the greatest rates of hydrogen evolution (Synechococcus 6803 and 602, Gloeobacter 7421 and Aphanocapsa montana) exhibited variation depending on the assay conditions with rates of hydrogen evolution in the dark being comparable to those obtained in the light, with the exception of Aphanocapsa montana. Carbon monoxide and acetylene, alone and/or together, either did not affect hydrogen evolution (Synechococcus 6301) or caused only low increases (Synechococcus 6803 and Gloeobacter 7421). Increases in hydrogen evolution rates by filamentous nitrogen-fixing strains due to carbon monoxide and acetylene addition can be partly explained by the action of these gases on various sites, binding and/or catalytic, that are present on the nitrogenase complex, in addition to their inhibitor effects on the uptake hydrogenase-mediated reaction (Bothe et al., 1978; Eisbrenner et al., 1978), although nitrogenase cannot be invoked in the present studies.

\section{Attempts to induce nitrogenase synthesis and activity}

Rippka \& Waterbury (1977) developed a technique to induce the synthesis and function of nitrogenase in non-heterocystous cyanobacteria in anaerobiosis. As found earlier for Synechococcus strains 6301, 6307 and 6803, Gloeobacter 7421 and Synechocystis 6714 (Rippka et al., 1974, 1979; Rippka \& Waterbury, 1977), no nitrogenase activity was detected in acetylene reduction assays of these cultures after transfer of late exponential/early stationary phase cells to anaerobic conditions. We obtained similar results with Aphanocapsa montana. We therefore conclude that a capacity to synthesize nitrogenase is not a pre-requisite for hydrogen evolution in the unicellular strains tested, and hence the hydrogen evolution recorded (Table 3) must be hydrogenase-mediated, via either an uptake hydrogenase acting in a reversible manner, or possibly a distinct functional hydrogenase acting in an evolution mode.

\section{Adaptation of cyanobacterial cultures with molecular hydrogen}

The growth of filamentous cyanobacteria with gas mixtures containing molecular hydrogen has been reported to increase hydrogenase levels when compared with aerobically grown cultures, suggesting that hydrogenase can be induced in cyanobacteria. Fujita et al. (1964) reported an activation of hydrogen consumption and production when filaments of aerobicallygrown Anabaena cylindrica were incubated for a few hours under hydrogen. Tel-Or et al. (1977) reported a 5- to 20-fold stimulation of hydrogenase activity in A. cylindrica and Nostoc muscorum following growth under an atmosphere containing $20 \%$ hydrogen, compared to aerobicallygrown cultures, and similar observations were reported (Eisbrenner et al., 1978) with six strains of cyanobacteria including Synechococcus 6301. Six unicellular strains were gassed with molecular hydrogen in an attempt to influence rates of hydrogen uptake and evolution (Table 4). Cultures were first grown aerobically at $25^{\circ} \mathrm{C}$ for $4 \mathrm{~d}$ and the resulting exponential phase cells were then transferred to growth under an atmosphere of $5 \%(\mathrm{v} / \mathrm{v})$ carbon dioxide in hydrogen for a further $4 \mathrm{~d}$, after which hydrogenase activities were assayed. Between 2- and 15-fold increases in hydrogen uptake and between 2- and 8-fold increases in hydrogen evolution occurred as a result of gassing cultures with molecular hydrogen. Molecular hydrogen has been reported to inhibit photosynthesis in Anabaena sp. TAl by inhibiting electron flow between photosystem II and photosystem I (Antarikanonda et al., 1980) whereas Peschek (1979a) has routinely grown Synechococcus under molecular hydrogen. 
Table 4. Increase in rates of hydrogen uptake and hydrogen evolution by six unicellular strains of cyanobacteria following adaptation with $5 \%$ carbon dioxide in hydrogen

Exponential phase cultures were gassed with $5 \%(\mathrm{v} / \mathrm{v})$ carbon dioxide in hydrogen using Quick-fit flasks and attachments (Methods) for $4 \mathrm{~d}$ before use. Percentage increases are the means of increases found in four or five assays using an identical rationale of treatments as used for aerobic control cultures (see legends to Tables 1 and 3). Each assay was done in duplicate. The percentage increases were calculated from the rates of hydrogen exchange by aerobic cultures. Absolute values are given in Tables 1 and 3 . ND, Not determined.

\begin{tabular}{lcc} 
& \multicolumn{2}{c}{ Percentage increase } \\
\cline { 2 - 3 } Hydrogen uptake & Hydrogen evolution \\
Synechococcus 6803 & 548 & 192 \\
Synechococcus 6301 & 580 & 432 \\
Synechococcus 6307 & 1500 & ND \\
Synechocystis 6714 & 279 & ND \\
Aphanocapsa montana & 203 & 824 \\
Gloeobacter 7421 & 300 & 270
\end{tabular}

\section{DISCUSSION}

The results reported here have confirmed and extended earlier findings on hydrogen exchange by Synechococcus 6301 (Peschek, 1979a,b,c, 1980; Bothe et al., 1980), and have characterized hydrogenase activity in a further eight strains of unicellular cyanobacteria from various groups. The absence of nitrogenase synthesis in anaerobiosis by all strains tested indicates that hydrogen exchange can occur in pure strains of unicellular cyanobacteria in the absence of nitrogenase activity and synthesis (Howarth et al., 1981).

Rates of hydrogen uptake and production vary from strain to strain, and the mechanism of hydrogen uptake in the unicellular strains appears to be similar to hydrogen uptake in the filamentous cyanobacteria as shown by assays in which oxygen was used, in conjunction with both light and dark assays. Prior addition of oxygen to the assays for hydrogen uptake in the light caused increases in the rate of hydrogen uptake by Synechococcus strains 602 and 6301, Gloeobacter 7421, Synechocystis strains 6308 and 6714 and by Aphanocapsa montana, but significant levels of anaerobic light-dependent hydrogen uptake occurred with Synechococcus strains 6803 and 6307, Synechocystis 6714 and $A$. montana, in agreement with one of the proposed modes of hydrogen uptake, a light anaerobic reaction (Peschek, 1979 b). Evidence for a second mode of hydrogen uptake, via an oxygen-dependent 'Knallgas' reaction, as demonstrated for Synechococcus 6301 (Peschek, 1979c), was found for all the strains used in the present study.

Increases in hydrogen uptake and production rates following exposure of the cultures to hydrogen may be explained by de novo protein synthesis, possibly involving the hydrogenase itself, or stimulation of pre-existing enzyme(s). However, this cannot be inferred directly from the results because the whole cell hydrogen uptake and production processes involve several components besides hydrogenase, including electron transport chain compounds, and it is not known how these additional components may be limiting, and how their levels may be changed by exposure to hydrogen.

The biological role of hydrogenase(s) in unicellular non-nitrogen-fixing cyanobacteria is little understood. A function in the recovery of hydrogen, obligatorily produced by nitrogenase, in the provision of reductant to nitrogenase and in the consumption of oxygen to protect nitrogenase (Dixon, 1972; Stewart, 1980; Stewart et al., 1982; Bothe, 1982) clearly cannot be invoked in this case. Hydrogen sulphide is the best documented source of reductant in cyanobacterial anoxygenic photosynthesis (Padan \& Cohen, 1982), but the use of hydrogen as an electron source for the photoreduction of nitrite, nitrate and carbon dioxide has been demonstrated with Synechococcus 6301 (Peschek, 1978, 1979b; Bothe et al., 1980). The production of hydrogen by 71 field isolates of cyanobacteria, although at low rates, is presumably largely via nitrogenase, since the organisms were selected for their ability to fix nitrogen (Berchtold \& Bachofen, 1979). 
The present results from nine pure cultures of unicellular strains suggests that the capacity to metabolize hydrogen via hydrogenase may be widespread among non-nitrogen-fixing cyanobacteria.

This work was supported by SERC.

\section{REFERENCES}

ANTARIKanonda, P., Berndt, H., Mayer, F. \& LORENZEN, H. (1980). Molecular hydrogen: a new inhibitor of photosynthesis in the blue-green alga (cyanobacterium), Anabaena sp. TAl. Archives of Microbiology 126, 1-10.

BerChtold, M. \& BaChofen, R. (1979). Hydrogen formation by cyanobacteria cultures selected for nitrogen fixation. Archites of Microbiology 123, 227 232.

BigGins, J. (1969). Respiration in blue-green algae. Journal of Bacteriolog. 99, 570-575.

Bothe, H. (1982). Nitrogen fixation. In Botanical Monographs, vol. 19, The Biology of Cyanobacteria, pp. 87-104. Edited by N. G. Carr \& B. A. Whitton. Oxford: Blackwell Scientific Publications.

Bothe, H., Tennigkeit, J., Eisbrenner, G. \& Yates, M. G. (1977a). The hydrogenase-nitrogenase relationship in the blue-green alga Anabaena cylindrica. Planta 133, 237-242.

Bothe, H., Tennigkeit, J. \& Eisbrenner, G. (1977 b). The utilization of molecular hydrogen by the bluegreen alga Anabaena cylindrica. Archives of Microbiology 114, 43-49.

Bothe, H., Distler, E. \& Eisbrenner, G. (1978). Hydrogen metabolism in the blue-green algae. Biochimie 60, 277-289.

Bothe, H., Neuer, G., Kalbe, I. \& Eisbrenner, G. (1980). Electron donors and nitrogenase in nitrogenfixing microorganisms. In Proceedings of an International Symposium on Nitrogen Fixation, pp. 83-112.

Chance, B. \& Hollunger, G. (1963). Inhibition of electron and energy transfer in mitochondria. I. Effects of amytal, thiopental, rotenone, progesterone and methylene glycol. Journal of Biological Chemistry 278, 4I8-43!

DixoN, R. O. D. (1972). Hydrogenase in legume root nodule bacteroids. Occurrence and properties. $A r$ chices of Microbiology 85, 193-201.

Eisbrenner, G., Distler, E., Floener, L. \& Bothe, H. (1978). The occurrence of the hydrogenase in some blue-green algae. Archives of Microbiology 118 , $177-184$

Frenkel, A. H., Gaffron, H. \& Battley, E. H. (1950). Photosynthesis and photoreduction in the blue-green alga, Synechococcus elongatus Näg. Bio$\log y$ Bulletin 99, 157-162.

Fujita, Y., Ohama, H. \& Hattori, A. (1964). Hydrogenase activity of a cell free preparation obtained from the blue-green alga Anabaena cylindrica. Plant and Cell Physiology 5, 305-314.

GafFron, H. \& RUBIN, J. (I942). Fermentative and photochemical production of hydrogen in algae. Journal of General Physiology 26, 219-240.

Gallon, J. R. (1981). The oxygen sensitivity of nitrogenase - a problem for biochemists and microorganisms. Trends in Biochemical Sciences 6, 19-23.
Gel'Man, N. S., Lukoyanova, M. A. \& Ostrovski, D. N. (1967). Respiration and Phosphorylation of Bacteria. New York: Plenum Press.

Haystead, A., Robinson, R. \& Stewart, W. D. P. (1970). Nitrogenase activity in extracts of heterocystous blue-green algae. Archives of Microbiology 75 , 235-243.

Houchins, J. P. \& Burris, R. H. (1981). Light and dark reactions of the uptake hydrogenase in Anabaena 7120. Plant Physiology 68, 712-716.

Howarth, D. C., Codd, G. A. \& Stewart, W. D. P. (1981). The uptake and evolution of molecular hydrogen by unicellular cyanobacteria. Society for General Microbiology Quarterly 8, 153.

LEMBERG, R. \& BARRETT, J. (1973). Cytochromes. London \& New York: Academic Press.

MaCKINNEY, G. (1941). Absorption of light by chlorophyll solutions. Journal of Biological Chemistry 140 , 315-322.

PADAN, E. \& Cohen, Y. (1982). Anoxygenic photosynthesis. In Botanical Monographs, vol. 19, The Biology of Cyanobacteria, pp. 215-235. Edited by N. G. Carr \& B. A. Whitton. Oxford: Blackwell Scientific Publications.

PescheK, G. A. (1978). Reduced sulfur and nitrogen compounds and molecular hydrogen as electron donors for anaerobic $\mathrm{CO}_{2}$ photoreduction in Anacystis nidulans. Archives of Microbiology 119, 313-322.

PESCHEK, G. A. (1979a). Evidence for two functionally distinct hydrogenases in Anacystis nidulans. Archives of Microbiology 123, 81-92.

PesCHeK, G. A. (1979b). Anaerobic hydrogenase activity in Anacystis nidulans. $\mathrm{H}_{2}$-dependent photoreduction and related reactions. Biochimica et biophysica acta 548, 187-202.

PesCheK, G. A. (1979c). Aerobic hydrogenase activity in Anacystis nidulans. The oxyhydrogen reaction. Biochimica et biophysica acta 548, 203-215.

PescheK, G. A. (1980). Electron transport reactions in respiratory particles of hydrogenase-induced $\mathrm{Ana}$ cystis nidulans. Archives of Microbiology 125, 123141

Peterson, R. B. \& Burris, R. H. (1978). Hydrogen metabolism in isolated heterocysts of Anabaena 7120. Archives of Microbiology 116, 125-132.

RIESKE, J. S. \& ZAUGG, W. S. (1962). The inhibition by antimycin $A$ of the cleavage of one of the complexes of the respiratory chain. Biochemical and Biophysical Research Communications 8, 421-426.

RIPPKA, R. \& WATERBURY, J. B. (1977). The synthesis of nitrogenase by non-heterocystous cyanobacteria. FEMS Microbiology Letters 2, 83-86.

RippKa, R., Waterbury, J. B. \& Cohen-Bazire, G. (1974). A cyanobacterium which lacks thylakoids. Archives of Microbiology 100, 419-436.

RiPPKA, R., DERUElles, J., WATERbURY, J. B., Herdman, M. \& Stanier, R. Y. (1979). Generic 
assignments, strain histories and properties of pure cultures of cyanobacteria. Journal of General Microbiology 111, 1-61.

Stanier, R. Y., Kunisawa, R., MANdel, M.\& CohenBAZIRE, G. (1971). Purification and properties of unicellular blue-green algae. (Order Chroococcales). Bacteriological Review's 35, 171-205.

STEWART, W. D. P. (1980). Some aspects of structure and function in $\mathrm{N}_{2}$-fixing cyanobacteria. Annual Retiew of Microbiology 34, 497-536.

Stewart, W. D. P., Fitzgerald, G. P. \& Burris, R. H. (1967). In situ studies on $\mathrm{N}_{2}$ fixation using the acetylene reduction technique. Proceedings of the national Academy of Sciences of the United States of America 58, 2071-2078.

Stewart, W. D. P., Hawkesford, M., Rowell, P. \& CODD, G. A. (1982). $\mathrm{H}_{2}$-production from sunlight and $\mathrm{H}_{2} \mathrm{O}$ - the role of the uptake hydrogenase in $\mathrm{N}_{2}-$ fixing cyanobacteria. In Solar Energy $R \& D$ in the European Community, series D, vol. 1, Photochemical, Photoelectrochemical and Photobiological Processes, pp. 165-169. Edited by D. O. Hall \& W. Palz. Dordrecht: D. Reidel.

Tel-Or, E., LuiJk, L. W. \& Packer, L., (1977). An inducible hydrogenase in cyanobacteria enhances $\mathrm{N}_{2}$-fixation. FEBS Letters 78, 49-52. 